Egyptian

Orthodontic Journal

\title{
THE CHANGE IN THE PERCEPTION OF MALOCCLUSION USING THE INDEX OF COMPLEXITY, OUTCOME AND NEED (ICON)
}

\author{
Mahasen Taha ${ }^{1}$ and Mona A Montasser ${ }^{1}$
}

\section{ABSTRACT:}

Background: Indices of orthodontics are systematic evaluations that measure the extent of deviation (malocclusion) from a standard. Aim: To investigate if there is a change in the patients perception of orthodontic malocclusion in this decade compared with the previous one using the Index of Complexity, Outcome and $\mathcal{N}$ eed (ICON). Materials and Methods: A total of 400 orthodontic study models were selected randomly. The study was designed to include two groups; the first group thus included 200 study models for patients who sought treatment before the year 2000, specifically between 1990 and 1999, and the second group included 200 study models for patients who sought treatment after the year 2000, specifically between 2000 and 2009. The study models were examined and occlusal traits were scored. Five occlusal traits were

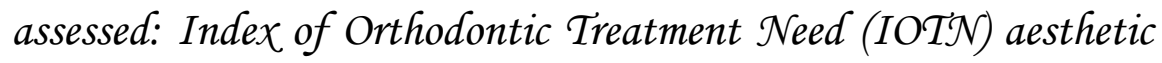
components, Overall upper arch crowding/spacing, Cross bite, Anterior vertical relationship (incisor overbite/openbite), Buccal segment antero-posterior relationship (right and left sides added together). Results: the results showed significant difference the treatment need assessment ( $P=.000)$, the complexity distribution $(\mathcal{P}=.000)$, occlusal trait distribution $(\mathcal{P}=.000)$, and aesthetic score distribution ( $P=.000)$, between the two groups. Conclusions: the predominant occlusal traits seen in patients sought orthodontic

\footnotetext{
${ }^{1}$ Lecturer, Department of Orthodontics, College of Dentistry, University of Mansoura, Mansoura, Egypt.
} 
Egyptian

Orthodontic Journal

treatment before the year 2000 were different than occlusal traits seen in patients sought orthodontic treatment after the year 2000. However, over the years, antero-posterior jaw relationship and dental crowding remained the main concerns for orthodontic patients.

\section{INTRODUCTION}

Orthodontic treatment aims to improve patients' dental health and appearance, as malocclusion has been associated with psychosocial distress patients' perception of their malocclusions is as important as the opinion of the orthodontist. Patient's perception of malocclusion is often not in agreement with objective measurements, studies found that some referrals refuse orthodontic treatment for professionally perceived handicapping malocclusions, while others ask for treatment of minor abnormalities. ${ }^{1,2}$

Indices of orthodontics are systematic evaluations that measure the extent of deviation (malocclusion) from a standard. The use of occlusal indices has become a fact of life in European orthodontics not only in determining access to public health orthodontics or level of co-payment, but also more recently, in quality assurance and research. ${ }^{3}$

The Index of Orthodontic Treatment Need (IOTN) or Peer Assessment Rating (PAR) Index have been validated against Uk dental opinions. ${ }^{4,5}$ The (IOTN) have been used by researchers in many countries ${ }^{6-8}$ and proved to be valid, reliable, and quick method to assess orthodontic treatment needs. ${ }^{9}$ The index comprises two parts; the Dental Health Component (DHC) which ranks malocclusions in terms of tooth irregularities and the Aesthetic Component (AC) which takes into consideration the aesthetic impairment.

Daniels and Richmond ${ }^{10}$ proposed an orthodontic index to assess treatment need, complexity, treatment improvement, and outcome (ICON) based on international professional opinion. The new index is relatively simple to use and having few triats to measure. Most of the measurement protocols are common to component of PAR or IOTN. Application of the index is relatively quick. It requires no measurement tools other than an ordinary millimeter ruler and an Aesthetic Component scale.

The purpose of this study was to investigate if there is a change in the patients perception of orthodontic malocclusion in this decade compared with the previous one using the (ICON). 
Egyptian

Orthodontic Journal

\section{MATERIALS AND METHODS}

A total of 400 orthodontic study models were selected randomly for a list of patients who sought orthodontic treatment at Al-Hada Military Hospital, Taif region Saudi Arabia. The study was designed to include two groups; the first group thus included 200 study models for patients who sought treatment before the year 2000, specifically between 1990 and 1999, and the second group included 200 study models for patients who sought treatment after the year 2000, specifically between 2000 and 2009.

The inclusion criteria included; study models with full permanent dentition (except third molars) and age range from 15 to 20 years. All selected cases did not have previous orthodontic treatment.

The study models were examined and occlusal traits were scored according to the protocol in Table 1. Five occlusal traits were assessed and these were:

1- IOTN aesthetic components: the dental aesthetic component of the IOTN ${ }^{10,11}$ was used. The dentition was compared to the scale graded from 1 for the most attractive to 10 the least attractive dental arrangement.

2- Overall upper arch crowding/spacing: this variable attempts to quantify the tooth to tissue discrepancy in the upper arch or the presence of impacted teeth in both arches. Estimation was done by naked eye. No attempt was done to include the curve of Spee or the degree of incisal inclination in the estimation. In the estimation process an impacted tooth in either the upper or lower arch scored the maximum for crowding

3- Cross bite: in the posterior region crossbite was deemed to be present if a transverse relation of cusp to cusp or worse existed in the buccal segment, this included buccal and lingual crossbites of one or more teeth. In the anterior segment crossbite was deemed to be present if an upper incisor or canine was present in edge to edge or lingual occlusion.

4- Anterior vertical relationship (incisor overbite/openbite): positive overbite was measured at the deepest part of the overbite on the incisor teeth. The open bite was measured with a millimeter ruler to the mid incisal edge of the most deviant upper tooth. 
5- Buccal segment antero-posterior relationship (right and left sides added together): the scoring zone included the canine, premolar and molar teeth. The scores for both sides were added together.

To assess the treatment need the five occlusal trait scores were then multiplied by there respective weightings and summed (Table2). If the total score was greater than 43 , this meant that treatment was indicated.

To determine the complexity level the total weight of the occlusal traits for the orthodontic record was compared to the cut-off values of the complex grade.

The five point grading of treatment complexity (simple, mild, moderate, difficult, very difficult) is summarized in Table 3.

Results were statistically analyzed with Chi-square test to detect signifcant differences between the scores of the two groups. Significance for all statistical tests was predetermined at $\mathrm{P}<.05$.

Table 1. Protocol for occlusal trait scoring

\begin{tabular}{|c|c|c|c|c|c|c|c|}
\hline & score & 0 & 1 & 2 & 3 & 4 & 5 \\
\hline Aesthetic & $\begin{array}{c}1-10 \text { as } \\
\text { judged using } \\
\text { IOTN AC }\end{array}$ & & & & & & \\
\hline $\begin{array}{l}\text { Upper arch } \\
\text { crowding }\end{array}$ & $\begin{array}{l}\text { Score only } \\
\text { the highest } \\
\text { trait }\end{array}$ & $\begin{array}{l}\text { Less than } \\
2 \mathrm{~mm}\end{array}$ & $2.1-5 \mathrm{~mm}$ & $5.1-9 \mathrm{~mm}$ & $9.1-13 \mathrm{~mm}$ & $13.1-17 \mathrm{~mm}$ & $\begin{array}{c}>17 \mathrm{~mm} \text { or } \\
\text { impacted } \\
\text { teeth }\end{array}$ \\
\hline Upper spacing & $\begin{array}{l}\text { Score only } \\
\text { the highest }\end{array}$ & Up to $2 \mathrm{~mm}$ & $2.1-5 \mathrm{~mm}$ & $5.1-9 \mathrm{~mm}$ & $>9 \mathrm{~mm}$ & & \\
\hline Crossbite & $\begin{array}{l}\text { Transverse } \\
\text { relationship } \\
\text { of cusp to } \\
\text { cusp or worse }\end{array}$ & $\begin{array}{c}\text { No } \\
\text { crossbite }\end{array}$ & $\begin{array}{l}\text { Crossbite } \\
\text { present }\end{array}$ & & & & \\
\hline Incisor openbite & $\begin{array}{c}\text { Score the } \\
\text { highest trait }\end{array}$ & $\begin{array}{c}\text { Complete } \\
\text { bite }\end{array}$ & $\begin{array}{c}\text { Less } \\
\text { than } 1 \mathrm{~mm}\end{array}$ & $1.1-2 \mathrm{~mm}$ & $2.1-4 \mathrm{~mm}$ & $>4 \mathrm{~mm}$ & \\
\hline Incisor overbite & $\begin{array}{c}\text { Lower } \\
\text { incisor } \\
\text { coverage }\end{array}$ & $\begin{array}{c}\text { Up to } \\
1 / 3-2 / 3 \\
\text { coverage }\end{array}$ & $\begin{array}{l}2 / 3 \text { up to } \\
\text { full } \\
\text { coverage }\end{array}$ & $\begin{array}{l}\text { Fully } \\
\text { covered }\end{array}$ & & & \\
\hline $\begin{array}{l}\text { Buccal segment } \\
\text { antero-posterior }\end{array}$ & $\begin{array}{l}\text { Left and } \\
\text { right sides } \\
\text { are added } \\
\text { together }\end{array}$ & $\begin{array}{l}\text { Cusp to } \\
\text { embrasure } \\
\text { relationship } \\
\text { Class } 1,2,3\end{array}$ & $\begin{array}{l}\text { Any cusp } \\
\text { relation up } \\
\text { to but not } \\
\text { including } \\
\text { cusp to cusp }\end{array}$ & $\begin{array}{c}\text { Cusp to } \\
\text { cusp } \\
\text { relationship }\end{array}$ & & & \\
\hline
\end{tabular}

Volume 36-December 2009 
Egyptian

Orthodontic Journal

Table 2: ICON variables and weightings

\begin{tabular}{|l|c|}
\hline \multicolumn{1}{|c|}{ Occlusal traits } & ICON weighting \\
\hline IOTN aesthetic component & 7 \\
\hline Buccal antero-posterior (left and right sides) & 3 \\
\hline Upper arch crowding & 5 \\
\hline Overbite & 4 \\
\hline Cross bite & 5 \\
\hline
\end{tabular}

Table 3: ICON complexity cut-off values

\begin{tabular}{|l|c|}
\hline \multicolumn{1}{|c|}{ Complexity grade } & Score range \\
\hline Simple & $<29$ \\
\hline Mild & $29-50$ \\
\hline Moderate & $51-63$ \\
\hline Difficult & $64-77$ \\
\hline Very difficult & $>77$ \\
\hline
\end{tabular}

\section{RESULTS}

The Chi-square tests showed significant difference in the treatment need assessment $(P=.000)$, complexity distribution $(P=.000)$, occlusal trait distribution $(P=.000)$, and aesthetic score distribution $(P=.000)$, between the two groups. The results of treatment need assessment (Table 4) showed that before year $200023 \%$ of the cases weighted less than 43 while $77 \%$ of the cases weighted more than 43 . After year $200060.5 \%$ of the cases weighted less than 43 while $39.5 \%$ cases weighted more than 43 .

The results (Table.5 and Fig. 1) showed that before the year 2000 only $6 \%$ of the orthodontic patients seeking treatment had simple malocclusion while after the year 2000 this category comprised $35 \%$ of the studied sample. The mild cases represented $29 \%$ of the cases before the year 2000 and presented $30 \%$ of the cases after the year 2000 . The moderate cases presented $19 \%$ of the cases before the year 2000 and $13 \%$ 
of the cases after the year 2000 . The difficult cases presented $22 \%$ of the cases before the year 2000 and $12 \%$ of the cases after the year 2000 while the very difficult cases presented $24 \%$ of the cases before the year 2000 and $10 \%$ of the cases after the year 2000 .

The results (Table.6 and Fig. 2) showed that the predominant malocclusions seen in patients seeking orthodontic treatment before the year 2000 were antero-posterior jaw relationship and deep bite followed by dental crowding and cross bite. After the year 2000 the predominant malocclusions were spacing, cross bite, followed by antero-posterior jaw relationship and dental crowding.

The results (Table. 7 and Fig. 3) showed that the highest frequency for the aesthetic scores before the year 2000 was for score 7; 30 cases, score 6; 29 cases, and scores 4 and 9; 26 cases. The highest frequency for the aesthetic scores after the year 2000 was for score $4 ; 34$ cases, score 2; 38 cases, and scores $3 ; 34$ cases.

Table 4: Treatment need assessment

\begin{tabular}{|l|c|c|}
\hline \multicolumn{1}{|c|}{ Weighted score } & Before2000 & After2000 \\
\hline Less than $\mathbf{4 3}$ & 46 & 121 \\
\hline more than 43 & 154 & 79 \\
\hline
\end{tabular}

$\mathrm{X}^{2}=57.82 \quad \mathrm{df}=1 \quad \mathrm{P}=.000$

* Significant at $\mathrm{P} \leq .05$

Table 5: ICON complexity distribution before and after the year 2000

\begin{tabular}{|l|c|c|}
\hline \multicolumn{1}{|c|}{ Complexity } & Before 2000 & After 2000 \\
\hline Simple & 12 & 70 \\
\hline Mild & 58 & 60 \\
\hline Moderate & 38 & 26 \\
\hline Difficult & 44 & 24 \\
\hline Very difficult & 48 & 20 \\
\hline
\end{tabular}

$\mathrm{X}^{2}=60.72 \quad \mathrm{df}=4 \quad \mathrm{P}=.000$

* Significant at $\mathrm{P} \leq .05$ 
Egyptian

Orthodontic Journal

Table 6: Occlusal triat distribution for the two groups; before the year 2000 and after the year 2000

\begin{tabular}{|l|c|c|}
\hline \multicolumn{1}{|c|}{ Occlusal triat } & Before 2000 & After 2000 \\
\hline Crowding & 102 & 65 \\
\hline Spacing & 40 & 73 \\
\hline Deep bite & 116 & 42 \\
\hline Open bite & 12 & 7 \\
\hline Cross bite & 60 & 73 \\
\hline B. segment anteroposterior & 122 & 60 \\
\hline
\end{tabular}

$\mathrm{X}^{2}=55.25 \quad \mathrm{df}=5 \quad \mathrm{P}=.000$

* Significant at $\mathrm{P} \leq .05$

Table 7: Aesthetic score distribution for the two groups; before the year 2000 and after the year 2000

\begin{tabular}{|c|c|c|}
\hline Aesthetic score & Before 2000 & After 2000 \\
\hline $\mathbf{1}$ & 0 & 38 \\
\hline $\mathbf{2}$ & 6 & 34 \\
\hline $\mathbf{3}$ & 18 & 43 \\
\hline $\mathbf{4}$ & 26 & 8 \\
\hline $\mathbf{5}$ & 18 & 18 \\
\hline $\mathbf{6}$ & 29 & 18 \\
\hline $\mathbf{7}$ & 30 & 18 \\
\hline $\mathbf{8}$ & 25 & 9 \\
\hline $\mathbf{9}$ & 26 & 10 \\
\hline $\mathbf{1 0}$ & 22 & \\
\hline
\end{tabular}

$\mathrm{X}^{2}=59.70 \quad \mathrm{df}=9 \quad \mathrm{P}=.000$

* Significant at $\mathrm{P} \leq .05$

Volume 36-December 2009 


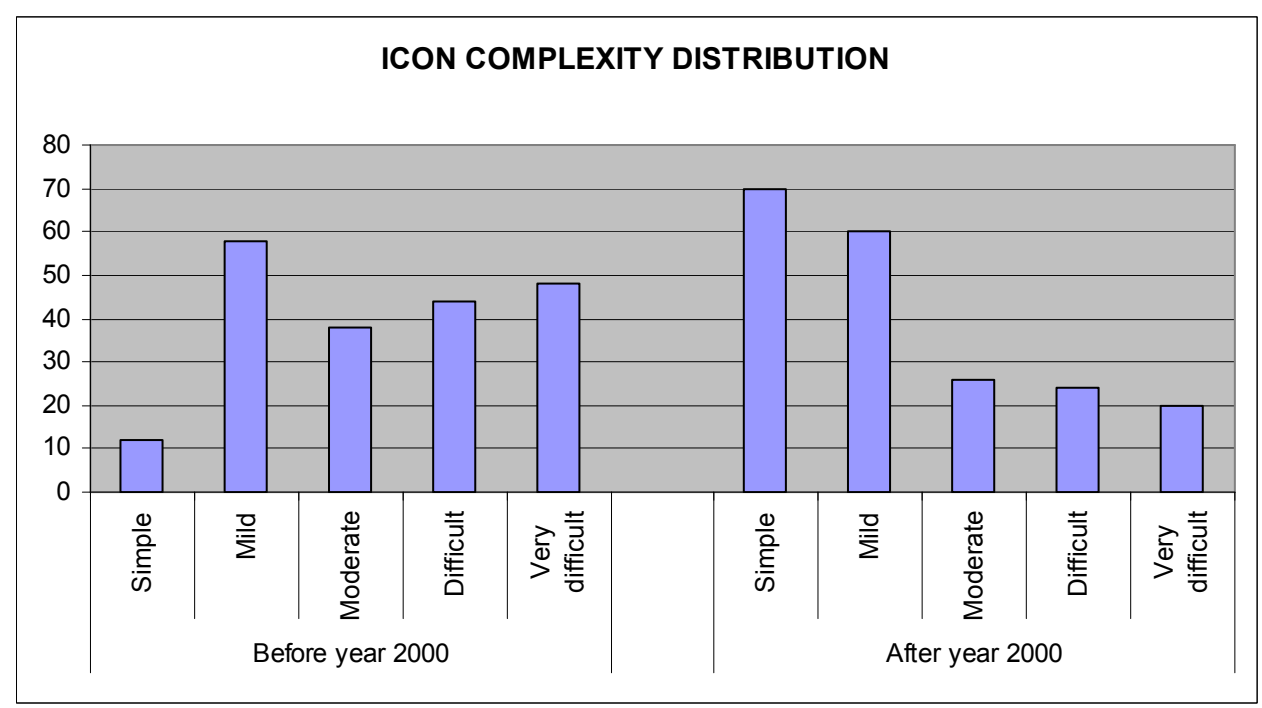

Fig.(1) ICON complexity distribution for the two groups; before the year 2000 and after the year 2000 .

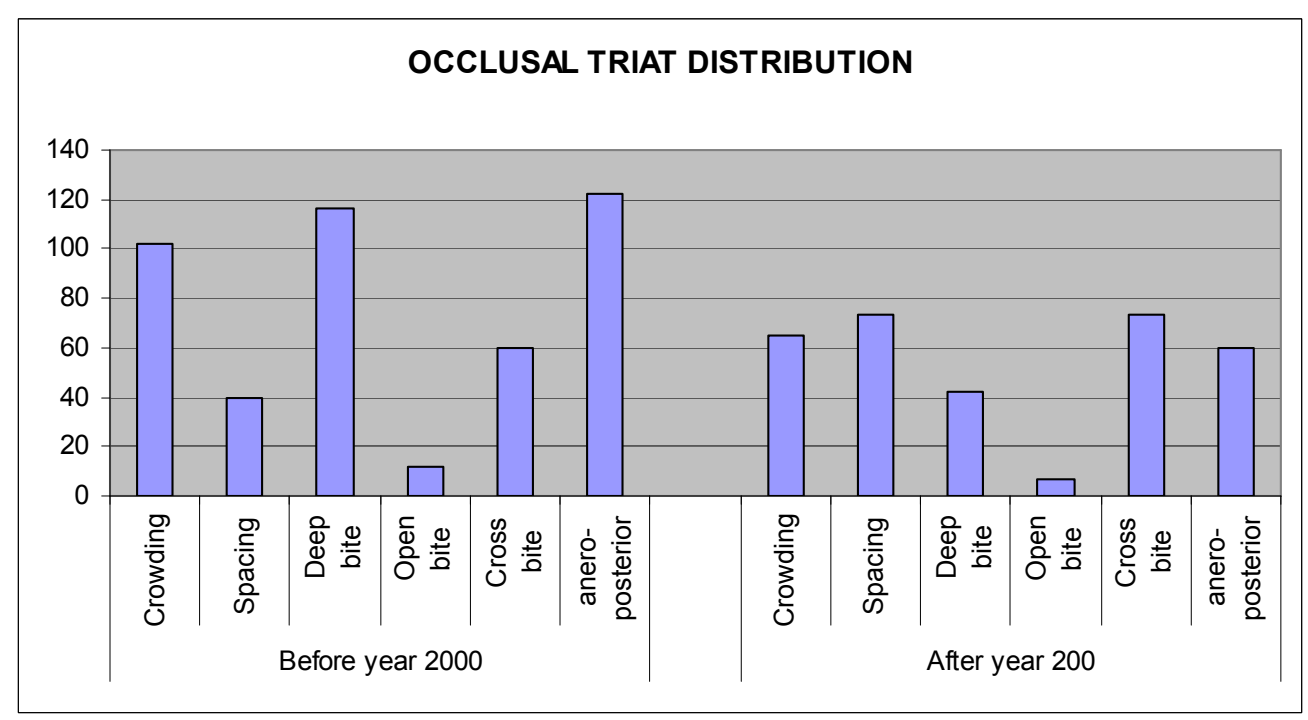

Fig.(2) Occlusal triat distribution for the two groups; before the year 2000 and after year the 2000.

Volume 36-Decem6er 2009 


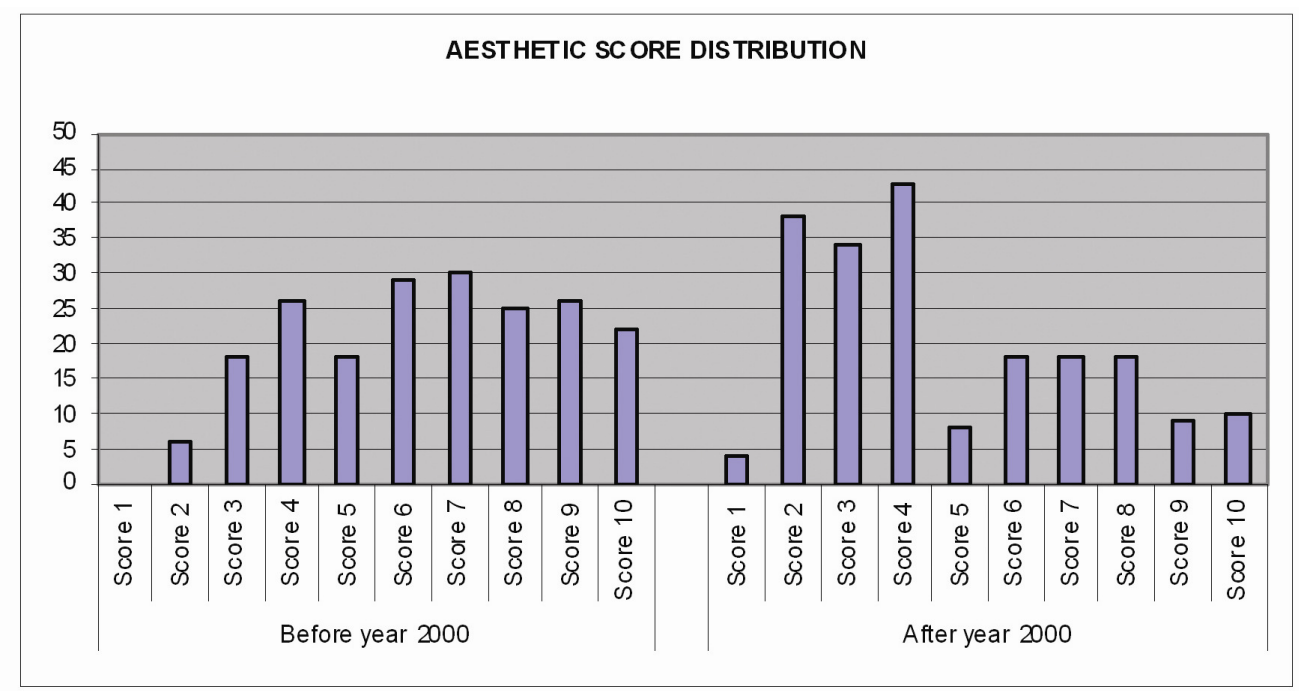

Fig.(3) Aesthetic score distribution for the two groups; before the year 2000 and after year the 2000 .

\section{DISCUSSION}

The spectrum of malocclusion ranges from near ideal to markedly anomalous. Orthodontic indices such as the Dental Aesthetic Index (DAI) and Index of Orthodontic Treatment Need (IOTN) evaluate the aesthetic and anatomic components of malocclusion. ${ }^{12}$ The provision of orthodontic treatment is thus to improve dental aesthetic, dental health and occlusal functioning. It is also for psychosocial adjustment, studies showed that orthodontic treatment is mainly motivated by personal concerns about appearance and other psychological factors. ${ }^{13,14}$

The results of this study showed a higher tendency for patients who, according to a professional evaluation using the ICON, are not indicated for orthodontic treatment to seek treatment. This is reflected in the treatment need assessment of the patients included in this study where a larger number of the patients seeking orthodontic treatment during this decade scored less than 43 as compared to the number of patients who had the same score in the previous decade. Looking at the ICON complexity distribution revealed that the number of patients with simple 
Egyptian

Orthodontic Journal

malocclusion seeking orthodontic treatment has increased dramatically in the group after the year 2000 and because of this we can see a relative decrease in the number of difficult and very difficult cases after the year 2000. The same tendency can be seen when looking at the aesthetic score distribution; before the year 2000 the highest frequencies were for a relatively high aesthetic score namely 7 and 6, while after the year 2000 the highest frequencies were for a relatively low aesthetic scores namely 4,3 , and 2. As Burden and Pine ${ }^{15}$ showed that adolescents (15-16 years old) who were scored by a trained examiner (using IOTN) as having similar dental aesthetics had similar perceptions of their malocclusion irrespective of their gender or social background, the results of the aesthetic score distribution in this study may be explained based on the fact that dental aesthetics has increasingly become in the focus of interest of the new generations. A recent study showed negative repercussions on daily living in Brazilian adolescents (14-18 years old) with malocclusions affecting anterior dental aesthetics. ${ }^{16}$ Although the age range in the present study is higher than the age range in these studies it could be considered comparable.

The results of this study also showed that the predominant occlusal traits seen in patients sought orthodontic treatment before the year 2000 were different than occlusal traits seen in patients sought orthodontic treatment after the year 2000. Before the year 2000 the predominant occlusal traits were antero-posterior jaw relationship and deep bite followed by dental crowding and cross bite. After the year 2000 the predominant malocclusions were spacing, cross bite, followed by dental crowding and antero-posterior jaw relationship. Thus the results showed that although there are changes in the occlusal triats distribution antero-posterior jaw relationship and dental crowding remained the main concerns for orthodontic patients. This finding is supported by the findings of other studies that people generally underestimate the malocclusion in the buccal segment in comparison with malocclusion in the anterior segment. ${ }^{17,18}$

A critical issue here is that the point at which the potential risks of treatment outweigh the potential benefits is a matter of contention and must be judged for the patient on an individual basis when assessing border line cases. ${ }^{19}$ 
Egyptian

Orthodontic Journal

\section{CONCLUSIONS}

1- There is a higher tendency in this decade for patients who are not indicated for orthodontic treatment to seek treatment.

2- The predominant occlusal traits seen in patients sought orthodontic treatment before the year 2000 were different than occlusal traits seen in patients sought orthodontic treatment after the year 2000 .

3- Over the years antero-posterior jaw relationship and dental crowding remained a main concern for orthodontic patients.

\section{REFERENCES}

1- Liepa A, Urtane I, Richmond S, Dunstan F. Orthodontic treatment need in Latvia. Eur J Orthod 2003;25:279-84.

2- O'brien KD, Fox N, McComb JL, Wright J: Factors influencing the uptake of orthodontic treatment. Br J Orthod 1996;23:331-4.

3- Shaw WC, Richmond S, O'Brien KD: The use of occlusal indices: A European perspective. Am J of Orthodo and Dentofacial Orthop 1995;107:1-10.

4- Richmond S, Shaw W C, O'Brien K D, Buchanan IB, Jones R, Stephens CD, Roberts CT, and Andrews M : The development of the PAR Index (Peer Assessment Rating) reliability and validity. Eur J Orthod 1995;14 :125-40.

5- Richmond S, Shaw W C, O'Brien K D, Buchanan IB, Stephens CD, Andrews M, and Roberts CT : The relationship between the index of orthodontic treatment and consensus opinion of a panel of 74 dentists. Br dent J 1995;178: 370-4.

6- Birkeland K, Bee O E, Wisth P J: Orthodontic concern among 11-year-old children and their parents compared with orthodontic treatment need assessed by Index of Orthodontic Treatment Need. Am J of Orthodo and Dentofacial Orthop 1996;110:197-205.

7- Hamdan A M: The relationship between patient, parent and clinician perceived need and normative orthodontic treatment need. Eur J Orthod 2004;26: 265-71. 
8- Josefsson E, Bjerklin K, Lindsten R: Malocclusion frequency in Swedish and immigrant adolescents - influence of origin on orthodontic treatment need. Eur J Orthod 2007; 29:79-87.

9- Burden D J, Holmes A : the need for orthodontic treatment in a child population of the united kingdom. Eur J Orthod 1994;16:395-9.

10- Daniels S and Richmond S: The development of the Index of Complexity, Outcome and Need (ICON). J Orthod 2000;27:149-62.

11- Shaw WC, Richmond S, O'Brien KD, Brook P, Stephens CD. Quality control in orthodontics: indices of treatment need and treatment standards. Br Dent J. 1991 170:107-12.

12- Onyeaso CO, Aderinokun GA. The relationship between Dental Aesthetic Index (DAI) and perceptions of aesthetics, function and speech amongst secondary school children in Ibadan, Nigeria. Int J Paediatr Dent 2003; 13:336-41.

13- Bernabé E, Flores-Mir C. Orthodontic treatment need in Peruvian young adults evaluated through dental aesthetics index. Angle Orthod 2006;76:417 - 21 .

14- Hamdan AM; Al-Omari IK, Al-Bitar ZB. Ranking dental aesthetics and thresholds of treatment need: a comparison between patients, Parents, and dentists. Eu J Orthod 2007;29:366-71.

15- Burden DJ, Pine CM. Self-perception of malocclusion among adolescents. Community Dent Health. 1995;12:89-92.

16- Marques LS, Filogônio CA, Filogônio CB, Pereira LJ, Pordeus IA, Paiva SM, Ramos-Jorge ML. Aesthetic impact of malocclusion in the daily living of Brazilian adolescents. J Orthod 2009.;36:152-9.

17- Mandall NA, Wright J, Conboy FM, O'Brien KD. The relationship between normative orthodontic treatment need and measures of consumer perception. Community Dent Health 2001;18:3-6.

18- Ahmed B, Gilthorpe MS, Bedi R. Agreement between normative and perceived orthodontic need amongst deprived multiethnic school children in London. Clin Orthod Res 2001;4:65-71.

19- Richmond S, Daniels C: International comparisons of professional assessments in orthodontics. Part 1: treatment need. Am J of Orthodo and Dentofacial Orthop 1998;113:180-5. 